\title{
BMJ Open Effectiveness and uptake of screening programmes for coronary heart disease and diabetes: a realist review of design components used in interventions
}

\author{
Carol Holland, Yvonne Cooper, Rachel Shaw, Helen Pattison, Richard Cooke
}

To cite: Holland C, Cooper Y, Shaw $\mathrm{R}$, et al. Effectiveness and uptake of screening programmes for coronary heart disease and diabetes: a realist review of design components used in interventions. BMJ Open 2013;3:e003428.

doi:10.1136/bmjopen-2013003428

- Prepublication history and additional material for this paper is available online. To view these files please visit the journal online (http://dx.doi.org/10.1136/ bmjopen-2013-003428).

Received 17 June 2013 Revised 27 September 2013 Accepted 11 October 2013

CrossMark

Health and Lifespan Psychology Group, School of Life \& Health Sciences, Aston University, Birmingham, UK

Correspondence to Dr Carol Holland; c.holland1@aston.ac.uk

\section{ABSTRACT}

Objective: To evaluate behavioural components and strategies associated with increased uptake and effectiveness of screening for coronary heart disease and diabetes with an implementation science focus.

Design: Realist review.

Data sources: PubMed, Web of Knowledge, Cochrane Database of Systematic Reviews, Cochrane Controlled

Trials Register and reference chaining. Searches limited to English language studies published since 1990.

Eligibility criteria: Eligible studies evaluated interventions designed to increase the uptake of cardiovascular disease (CVD) and diabetes screening and examined behavioural and/or strategic designs. Studies were excluded if they evaluated changes in risk factors or cost-effectiveness only.

Results: In 12 eligible studies, several different intervention designs and evidence-based strategies were evaluated. Salient themes were effects of feedback on behaviour change or benefits of health dialogues over simple feedback. Studies provide mixed evidence about the benefits of these intervention constituents, which are suggested to be situation and design specific, broadly supporting their use, but highlighting concerns about the fidelity of intervention delivery, raising implementation science issues. Three studies examined the effects of informed choice or loss versus gain frame invitations, finding no effect on screening uptake but highlighting opportunistic screening as being more successful for recruiting higher CVD and diabetes risk patients than an invitation letter, with no differences in outcomes once recruited. Two studies examined differences between attenders and non-attenders, finding higher risk factors among non-attenders and higher diagnosed CVD and diabetes among those who later dropped out of longitudinal studies.

Conclusions: If the risk and prevalence of these diseases are to be reduced, interventions must take into account what we know about effective health behaviour change mechanisms, monitor delivery by trained professionals and examine the possibility of tailoring programmes according to contexts such as risk level to reach those most in need. Further research is needed to determine the best strategies for lifelong approaches to screening.
Strengths and limitations of this study

- The study's strength is its focus on what contributes to the success and the reach of screening plus intervention studies, based on health psychology evidence.

- Its evaluation of the degree and fidelity with which evidenced health behaviour strategies are used has important implications for practitioners managing screening and intervention programmes.

- Evaluation of opportunistic screening confirms previous work showing that it reaches people with higher cardiovascular disease risk factors than those reached using standard invitations, but additionally demonstrates that people screened opportunistically show very similar improvements in assessed risk factors and behaviours to people invited in other ways.

- This review raised two key challenges. First, many studies do not analyse behavioural components of the intervention design discretely, making it impossible to discern which factors are at work in producing the observed effects. Second, the heterogeneity of outcome measures precludes statistical evaluations using meta-analysis.

- Publication or outcome bias may have affected our results, though not all included studies found significant reductions in assessed risk or differences in outcomes between the intervention and control groups.

- Several potentially relevant studies focusing on the design of screening interventions were excluded because they were not delivered in healthcare settings.

- Well-known selective dropout ('selective attrition') biases are confirmed in these studies, whereby people with more lifestyle risk factors (smoking, higher alcohol consumption, overweight) are more likely to fail to return for follow-up appointments. Careful methodological and statistical controls are needed to reduce resultant effects on findings, but few studies employ these.

- As a realist review, this document examines outcomes which may be situation specific. The acknowledgement that some findings may be situation specific is important in the generalisation of results. 


\section{INTRODUCTION}

Previous reviews of multiple risk factor interventions for primary prevention of coronary heart disease (CHD) and diabetes often conclude that interventions have no overall effect on mortality. ${ }^{1}$ Nevertheless, CHD deaths have halved in the UK and other developed countries in the last 30 years. ${ }^{2}$ Unal $e t a l^{3}$ compared targeted interventions and general population screening. They estimated the proportion of reduced deaths from CHD in England and Wales between 1981 and 2000 that were attributable to changes in risk factors in patients with CHD or changes in cardiovascular risk factors in the general population, and found both approaches beneficial. These authors calculated that reductions in risk factors (such as smoking and high blood pressure) in the general population account for $50-75 \%$ of the fall in cardiac deaths, and that pharmacological and surgical treatments for diagnosed CHD patients account for 25$50 \%$. $^{3}$ However, that benefit was greater when individuals without CHD were screened: results indicated an additional 21 years of life for each death prevented in those with no CHD diagnosis compared with 7.5 years for those with CHD.

Public health campaigns to reduce these conditions usually involve: government-sponsored programmes at the population level or changes in policy (such as food labelling legislation); targeted interventions for those at heightened risk (eg, moderate-intensity, low-impact exercise for those very overweight or with chronic conditions); or general population screening and intervention to reduce risk development in the healthy population and identify high-risk people leading to specific referral for detected or previously untreated symptoms (eg, current National Health Service Health Check $^{4}$ programme).

This review focuses on quantitative evaluations of screening plus intervention programmes that target the general population to reduce the incidence of CHD and diabetes. These conditions were selected because they are the focus of screening programmes in many countries and the negative outcomes of these conditions can be ameliorated by lifestyle behaviour change. Previous reviews have focused on reductions in risk measurements, cost-effectiveness or years of life added. ${ }^{1}$ In contrast, the primary objective of this review was to examine the use of behaviour change features embedded within intervention designs of screening programmes targeting $\mathrm{CHD}$ and diabetes and their impact on health outcomes. A secondary objective was to evaluate the factors predicting attendance and attrition from these programmes.

These objectives are not well suited to systematic review and meta-analysis approaches, where the aim is to synthesise results across contexts to gain a sense of the pattern of results for studies conducted using similar methodologies. In contrast, the present paper was focused on questions around 'how' and 'why' behavioural features are incorporated into interventions, and how these features can contribute to the success of interventions. Therefore, we adopted a realist review, also called a meta-narrative approach. This approach was adopted to gain insights into the direction in which the evidence is pointing and the underlying theoretically driven concepts, behaviour change mechanisms and barriers, which may combine to contribute to outcomes in population screening for CHD and diabetes. ${ }^{5}$ Focus on the mechanisms and use of evidence-based behaviour change strategies locate the review within an implementation science approach, given that 'one of the most consistent findings from clinical and health services research is the failure to translate research into practice and policy' (Ref. ${ }^{6}$, p.1)

A realist methodology ${ }^{7}$ is suited to areas where there is a diverse literature, which may have a variety of methods, components and outcomes. This methodology is concerned with explaining more fully the processes of interventions within the complexity of their contexts, rather than focusing on simple cause and effect deterministic theories. Realist reviews can 'contribute to programme understandings even when the outcomes are not rigidly defined at the outset of the review and have been characterised as a theory-driven and interpretive approach to systematic reviews to answer questions about what works, for whom and in what circumstances' (Ref. ${ }^{8}$, p.4).

Inclusion of studies in a realist review is intended to be less proscribed than in a systematic review to allow for a mix of methods and outcomes to be included, ensuring that underlying theories and approaches can be evaluated rather than a focus on specific measured outcomes. Inclusion criteria in this review of screening plus intervention studies were generated using guidance from systematic reviews on screening (PRISMA), ${ }^{9}$ but were further generated iteratively using the themes that emerged. The flow chart and checklist are available as supplementary material.

\section{Data sources}

Web of Knowledge, PubMed, Cochrane Database of Systematic Reviews and Cochrane Controlled Trials Register restricted to the English language and published post-1990. Reference chaining of identified studies was then conducted.

\section{Search strategy}

Search terms were adapted from previous Cochrane reviews of screening plus uptake studies. ${ }^{10} 11$ The full strategy is available in appendix 1. The search was first carried out in July 2010 and updated in March 2013.

\section{Study selection}

The initial inclusion criteria were: studies that tested interventions designed to increase uptake of CHD and diabetes screening programmes or to increase early detection and prevention of these conditions and examined the behavioural and/or strategic design of the intervention tested. Studies which only reported on 
changes in risk factors or cost-effectiveness were excluded.

The initial search elicited 2323 relevant published papers. The retrieved papers were screened according to the inclusion criteria. Details of the screening and exclusion stages are detailed in figure 1.

Following the screening of titles, 565 relevant papers remained. The reference lists and citations of these papers were searched (using PubMed and Web of Knowledge) specifically to identify studies that evaluated the behavioural aspects of the interventions tested; a pragmatic approach was taken to ensure that articles which may not have been found using such traditional chaining were not missed, in that new keywords elicited from themes of identified articles were added to the search, notably on specific behavioural approaches. An example was 'informed choice invitation'. This process identified a further 16 articles. Following the removal of duplicates across sources (120), and removal after abstract screening (304), two authors (CH and YC) independently reviewed 157 full-text papers and further excluded studies which only evaluated changes in risk factors or cost-effectiveness. Further exclusions at the abstract and full-text stages were guided by framing of the interventions into their constituent components using the Population, Intervention, Comparison, Outcome and Type of study design (PICO $(\mathrm{T})$ categories. The review was concerned with general population (adult) screening, and so interventions that considered only those already identified as being at high risk of cardiovascular disease (CVD)/diabetes or already receiving treatment, younger or a specific age or disease-limited

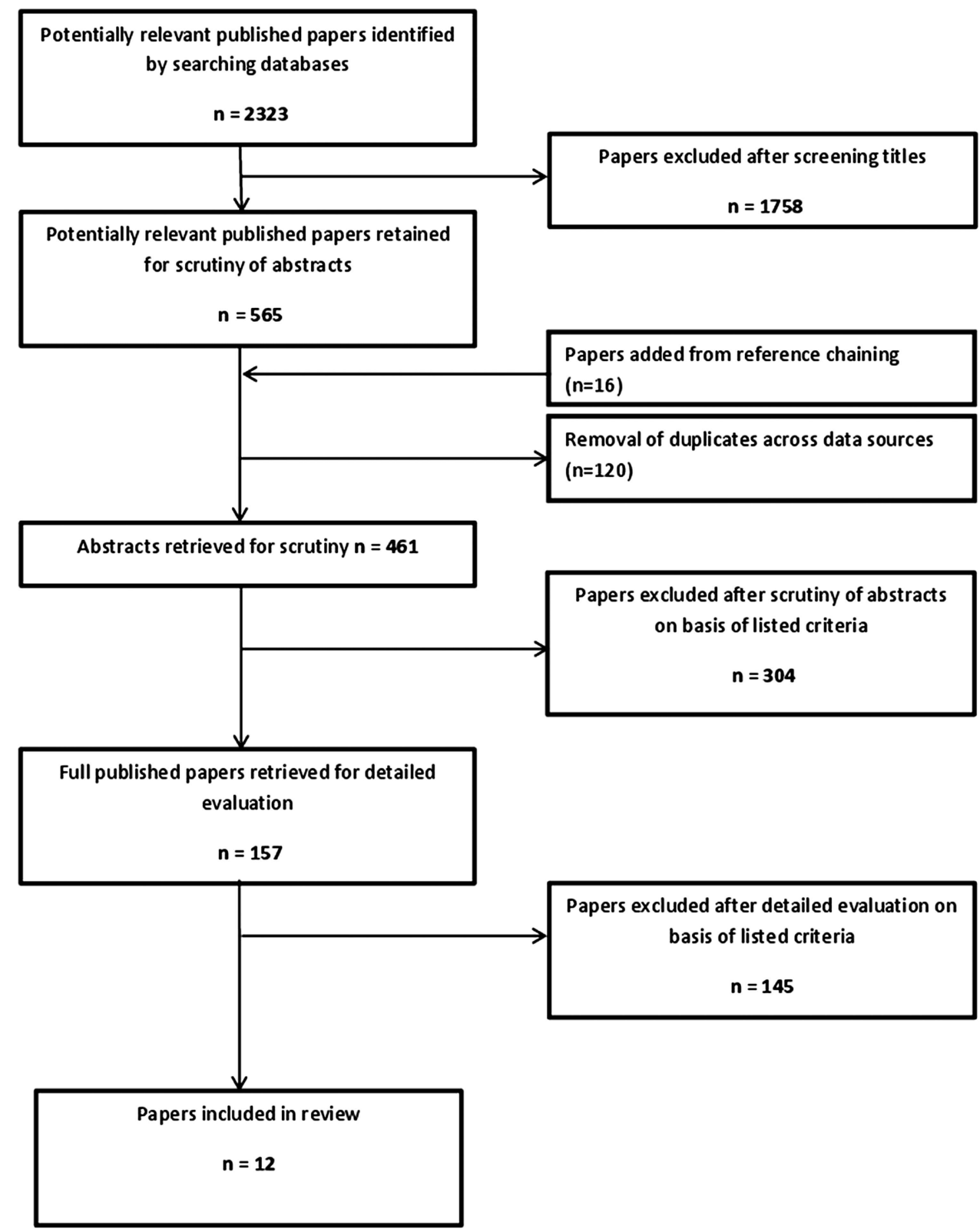

Figure 1 Flow chart of intervention studies included and excluded from this review. 
groups were excluded. Although the initial reading included interventions in a variety of settings, the selection of the final set of papers restricted inclusion to studies set in primary healthcare, in line with the aim of this review being to inform primary healthcare-based interventions. Comparison with a control group of some nature was necessary for inclusion, and although most of the identified studies did consist of randomised or cluster randomised control trials, other designs were not excluded, and the relevant quality appraisal criteria for the different designs were used as appropriate (table 1). Although most of the studies examined outcomes in terms of a successful or unsuccessful lowering of CVD or diabetic risk, the intention of this review was to determine 'how, why and what works' or what may prevent it from working, ${ }^{7}$ so the outcome type was not restricted.

A preliminary examination of studies sought to extract dominant themes reflecting the behavioural features of 'how and why' such interventions succeed or fail in reducing CVD or diabetic risk. Most studies examined the effect of a multicomponent intervention, in which key features were engaging populations in screening, providing screened populations with feedback about risk status, a health dialogue (defined as counselling that includes aspects of shared decision-making such as goal setting or intention formation, and is not just information giving or psychological support), information about the impact of risk factors on illness development, counselling, motivational interviewing (MI), referral and pharmacological treatment. The impact of feedback and health dialogue on health outcomes was reported, but due to the multiple constituents of interventions, isolating the effects of any one feature is often difficult. Search for studies that focused on explicitly examining such features therefore developed. Twelve studies were left that fulfilled this requirement and met the inclusion criteria. Details of the components covered by these papers, year of publication, samples recruited, populations studied and main findings are presented in table 1. The selection process is summarised in a PRISMA flow diagram.

\section{Data extraction}

Two reviewers ( $\mathrm{CH}$ and $\mathrm{YC})$ independently extracted information from each article, and one author $(\mathrm{CH})$ reviewed all the studies. Data were extracted on the study authors, geographical location, year of publication, study cohort characteristics, behavioural design features of the intervention and outcome measures (see table 1).

\section{RESULTS}

\section{Study characteristics and quality}

The SIGN 50 assessment of quality of studies included is summarised in table 1. Two authors ( $\mathrm{CH}$ and $\mathrm{RC}$ ) independently rated each included study for quality using the SIGN 50 guidelines, ${ }^{12}$ with each study rated as $++=$ high quality, $+=$ acceptable quality or $0=$ low quality.
After independent ratings, the authors met to discuss their ratings. All disagreements were resolved through discussion. Seven studies were of acceptable quality and five were high-quality studies. The key elements of the studies are summarised in table 1, so that key themes and evidence from the papers could be identified and extracted for examination.

The review of included papers begins by describing studies that addressed the question of what impact behaviour change features embedded within intervention designs of CVD and diabetes screening programmes have on health outcomes. The review then proceeds to cover literature that evaluates the factors predicting attendance and attrition from screening and intervention programmes.

\section{Impact of feedback on behaviour change}

Providing people with feedback on their behaviour can prompt behaviour change, ${ }^{13} 14$ and has been recognised as an effective behaviour change technique in Abraham and Michie's behaviour change taxonomy. ${ }^{15}{ }^{16}$ In general, there are two types of feedback: informing patients about their risk status, for example, of CVD; and giving patients behaviour-specific feedback, for example, discussion related to detailed dietary analysis ${ }^{17}$ with a key point of contention being the effectiveness and practicalities of these two approaches. Two studies examined the impact of feedback on behaviour change.

Aubin $e t a l^{18}$ investigated whether knowledge of blood cholesterol level affected intention to adopt a low fat diet. The study was conducted in hospital-based family medical centres in Quebec, Canada. Participants were randomly assigned to complete a questionnaire about CVD risk profile, intention to adopt a low fat diet and dietary fat intake either before or after receiving their screening results, that is, one group knew their results, and one did not at the time of completing the questionnaire. Patients who were aware of their blood screening results before they completed the questionnaire showed a significantly higher intention to adopt a lower fat diet than patients who were not $\left(\mathrm{F}_{1,417}=5.4, \mathrm{p}<0.02\right)$. In addition, in those who had received their results, intention tended to rise with the blood cholesterol level (nonsignificant, $\mathrm{F}_{5,413}=2.0, \mathrm{p}<0.08$ ).

Three months after screening, participants' dietary fat intake and changes in eating habits were assessed by comparing their diet with that reported at baseline. Data for 391 participants (mean age $=35$ years) were analysed. The mean dietary fat intake reduced significantly from $48.5 \mathrm{~g} /$ day at baseline to $37.7 \mathrm{~g} /$ day at 3-month follow-up for the participant group as a whole. After 3 months, patients who had abnormal cholesterol levels had a significantly greater reduction in dietary fat intake than patients with normal cholesterol results $(\mathrm{F}(2,388)$ $=3.6, \mathrm{p}=0.03$ ); correlational analysis showed a highly significant link between reduction in fat intake and reduction in blood cholesterol (the researchers report an $\mathrm{R}^{2}$ of $0.5, \mathrm{p}=0.001$, but confirmed by email that a Pearson's 
Table 1 Included studies

\begin{tabular}{|c|c|c|c|c|c|c|c|}
\hline Study & Country & Sample & $\mathbf{N}$ & Design & $\begin{array}{l}\text { Intervention } \\
\text { component }\end{array}$ & Main findings & Quality \\
\hline Aubin et $a l^{18}$ & Canada & $\begin{array}{l}58 \% \text { female, mean age } \\
35 \text { years }\end{array}$ & 391 & $\begin{array}{l}\text { RCT, controls completed } \\
\text { questionnaire on intention to eat a low } \\
\text { fat diet before they received results of } \\
\text { cholesterol screening, intervention } \\
\text { participants completed it after. }\end{array}$ & $\begin{array}{l}\text { Impact of feedback } \\
\text { on behaviour } \\
\text { change }\end{array}$ & $\begin{array}{l}\text { Intervention participants were more } \\
\text { likely to intend to adopt a low fat diet } \\
\text { than controls. Patients with abnormally } \\
\text { high cholesterol( }>6.3 \mathrm{mmol} / \mathrm{L}) \text { showed } \\
\text { a greater reduction in dietary fat intake } \\
\text { than those who had a normal } \\
\text { cholesterol }(<5.2 \mathrm{mmol} / \mathrm{L}) \text {. }\end{array}$ & + \\
\hline Elton et al $1^{19}$ & England & $\begin{array}{l}44 \% \text { female, mean age } \\
37.9 \text { years }\end{array}$ & 469 & $\begin{array}{l}\text { Prospective, blinded RCT, intervention } \\
\text { participants knew their cholesterol } \\
\text { level before the health education and } \\
\text { diet session, control participants did } \\
\text { not. }\end{array}$ & $\begin{array}{l}\text { Impact of feedback } \\
\text { on behaviour } \\
\text { change }\end{array}$ & $\begin{array}{l}\text { Participants whose initial serum } \\
\text { cholesterol was } \geq 6.5 \mathrm{mmol} / \mathrm{L} \text {, and who } \\
\text { had been informed of this, showed a } \\
\text { significantly greater reduction in serum } \\
\text { cholesterol than control participants in } \\
\text { the same high cholesterol group who } \\
\text { had not been informed. All participants } \\
\text { received the same dietary advice. }\end{array}$ & ++ \\
\hline Färnkvist et $a^{R 0}$ & Sweden & $\begin{array}{l}100 \% \text { male, age } \\
\text { stratified, aged } 66,56 \\
\text { and } 46 \text { years }\end{array}$ & 817 & $\begin{array}{l}\text { Cross-sectional study. Screening only, } \\
\text { screening plus health dialogue by } \\
\text { trained professionals and } \\
\text { non-participants compared. }\end{array}$ & $\begin{array}{l}\text { Benefits of health } \\
\text { dialogue over } \\
\text { simple feedback }\end{array}$ & $\begin{array}{l}\text { ORs of developing diabetes or CVD } \\
\text { over } 11 \text { years were } 2.5 \text { for those who } \\
\text { had received screening with no health } \\
\text { dialogue and } 3.0 \text { for those who had not } \\
\text { participated in the original screening, } \\
\text { as compared with those who had } \\
\text { received screening plus a structured, } \\
\text { motivational health dialogue. }\end{array}$ & + \\
\hline Engberg et $a^{21}$ & Denmark & $\begin{array}{l}52 \% \text { female, mean age } \\
40.4 \text { years }\end{array}$ & 1507 & $\begin{array}{l}\text { RCT, screening, screening plus health } \\
\text { dialogue compared with a normal care } \\
\text { control group. }\end{array}$ & $\begin{array}{l}\text { Benefits of health } \\
\text { dialogue over } \\
\text { simple feedback }\end{array}$ & $\begin{array}{l}\text { After } 5 \text { years, there were no differences } \\
\text { between the two intervention groups. } \\
\text { Total intervention/control Risk Ratio } \\
\text { was } 0.54 \text {. Absolute risk reduction was } \\
8.6 \% \text {. }\end{array}$ & ++ \\
\hline Rubak et $a^{22}$ & Denmark & $\begin{array}{l}42 \% \text { female, mean age } \\
61 \text { years. Patients with } \\
\text { screen-detected type } 2 \\
\text { diabetes }\end{array}$ & 628 & $\begin{array}{l}\text { Cluster RCT, intervention and control } \\
\text { groups received training in intensive } \\
\text { treatment of diabetes, intervention } \\
\text { group GPs additionally received } \\
\text { training in motivational interviewing } \\
\text { (MI) and were instructed to use it. }\end{array}$ & $\begin{array}{l}\text { Benefits of health } \\
\text { dialogue over } \\
\text { simple feedback }\end{array}$ & $\begin{array}{l}\text { No effect of motivational interview on } \\
\text { medication adherence or metabolic } \\
\text { status relative to the control group. } \\
\text { Medication adherence across both } \\
\text { groups was almost } 100 \% \text {, both groups } \\
\text { showed significant improvements in all } \\
\text { risk measures. Key issues were lower } \\
\text { than the planned use of motivational } \\
\text { interview by intervention group GPs, } \\
\text { and contamination of methods and } \\
\text { training into control group GPs }\end{array}$ & ++ \\
\hline $\begin{array}{l}\text { Koelewijn-van } \\
\text { Loon et } a \text { R }^{3}\end{array}$ & Netherlands & $\begin{array}{l}55 \% \text { female, mean age } \\
57 \text { years }\end{array}$ & 615 & $\begin{array}{l}\text { Cluster } \mathrm{RCT} \text {, intervention nurses } \\
\text { received training to use risk. }\end{array}$ & & $\begin{array}{l}\text { Outcome measures were self-reported } \\
\text { lifestyle measures. No differences }\end{array}$ & + \\
\hline
\end{tabular}




\begin{tabular}{|c|c|c|c|c|c|c|c|}
\hline Study & Country & Sample & $\mathbf{N}$ & Design & $\begin{array}{l}\text { Intervention } \\
\text { component }\end{array}$ & Main findings & Quality \\
\hline & & & & $\begin{array}{l}\text { assessment, communication, a } \\
\text { decision support tool and MI. Control } \\
\text { group nurses received training on risk } \\
\text { assessment and applied usual care. }\end{array}$ & $\begin{array}{l}\text { Benefits of health } \\
\text { dialogue over } \\
\text { simple feedback }\end{array}$ & $\begin{array}{l}\text { between control and intervention } \\
\text { groups were noted at } 12 \text {-week } \\
\text { follow-up, but overall both groups } \\
\text { showed improvements. }\end{array}$ & \\
\hline Craigie et $a f^{24}$ & Scotland & $\begin{array}{l}72 \% \text { female, mean age } \\
54.5 \text { years, high risk but } \\
\text { not on statins }\end{array}$ & 75 & $\begin{array}{l}\text { RCT, intervention-motivational } \\
\text { interview and volitional aspects to } \\
\text { change planned behaviour, control } \\
\text { group usual care. }\end{array}$ & $\begin{array}{l}\text { Benefits of health } \\
\text { dialogue over } \\
\text { simple feedback }\end{array}$ & $\begin{array}{l}\text { Percentage achieving } 5 \text { portions of fruit } \\
\text { and vegetables a day and weight } \\
\text { maintenance or loss indicators was } \\
\text { significantly better in the intervention } \\
\text { group over the } 12 \text {-week follow-up. } \\
\text { Control group made no positive } \\
\text { change. }\end{array}$ & + \\
\hline Marteau et $a^{26}$ & England & $\begin{array}{l}47.6 \% \text { female, mean age } \\
57.4 \text { years }\end{array}$ & 1272 & $\begin{array}{l}\mathrm{RCT} \text {, informed choice invitation } \\
\text { compared with standard invitation. }\end{array}$ & $\begin{array}{l}\text { Impact of type of } \\
\text { invitation on } \\
\text { uptake and } \\
\text { outcome }\end{array}$ & $\begin{array}{l}\text { Primary outcome of attendance did not } \\
\text { differ between groups. Secondary } \\
\text { outcome of intention to change health } \\
\text { behaviour was unaffected by invitation } \\
\text { type. }\end{array}$ & ++ \\
\hline Park et $a^{27}$ & England & $\begin{array}{l}66.6 \% \text { male, mean age } \\
58 \text { years }\end{array}$ & 116 & $\begin{array}{l}\mathrm{RCT} \text {, loss frame compared with gain } \\
\text { frame invitation. }\end{array}$ & $\begin{array}{l}\text { Impact of type of } \\
\text { invitation on } \\
\text { uptake and } \\
\text { outcome }\end{array}$ & $\begin{array}{l}\text { Primary outcome of attendance did not } \\
\text { differ between groups (invitation types). } \\
\text { Secondary outcome measures of } \\
\text { anxiety, self-perceived health and } \\
\text { illness representation also did not differ } \\
\text { between groups. }\end{array}$ & ++ \\
\hline Hellénius et $a^{28}$ & Sweden & $\begin{array}{l}65 \% \text { female, age range } \\
20-60 \text { years }\end{array}$ & 4904 & $\begin{array}{l}\text { Observational cross-sectional study, } \\
\text { those screened as a result of } \\
\text { opportunistic invitations compared } \\
\text { with those responding to a letter } \\
\text { invitation. }\end{array}$ & $\begin{array}{l}\text { Impact of type of } \\
\text { invitation on } \\
\text { uptake and } \\
\text { outcome }\end{array}$ & $\begin{array}{l}\text { Opportunistically screened participants } \\
\text { showed higher CVD risk factors than } \\
\text { letter invited participants at baseline. } \\
\text { Effectiveness of screening in lowering } \\
\text { risk factors did not differ between the } \\
\text { two groups. }\end{array}$ & + \\
\hline Jones et $a^{p 9}$ & Wales & $\begin{array}{l}53.4 \% \text { female, mean age } \\
42.5 \text { years }\end{array}$ & 2542 & $\begin{array}{l}\text { Observational cross-sectional study, } \\
\text { those not responding to initial } \\
\text { invitations to screenings compared } \\
\text { with those who did. }\end{array}$ & $\begin{array}{l}\text { Differences } \\
\text { between attenders } \\
\text { and non-attenders }\end{array}$ & $\begin{array}{l}\text { Non-attenders showed more risk } \\
\text { factors than attenders. }\end{array}$ & + \\
\hline Thomas et $a{ }^{\beta 0}$ & England & $\begin{array}{l}100 \% \text { male, mean age } \\
69.1 \text { years }\end{array}$ & 5655 & $\begin{array}{l}\text { Observational cross-sectional study, } \\
\text { health characteristics of those who } \\
\text { attended and those who did not } \\
\text { attend a } 20 \text {-year follow-up were } \\
\text { compared. }\end{array}$ & $\begin{array}{l}\text { Differences } \\
\text { between attenders } \\
\text { and non-attenders }\end{array}$ & $\begin{array}{l}\text { Despite no differences at baseline in } \\
\text { BMI and cholesterol, those who later } \\
\text { dropped out of a longitudinal study had } \\
\text { higher blood pressure at baseline and a } \\
\text { greater number of CVD and bronchial } \\
\text { diagnoses, and adverse lifestyle factors } \\
\text { (eg, OR of smoking in non-attenders } \\
\text { 2.33). }\end{array}$ & + \\
\hline
\end{tabular}

Note: SIGN 50 cohort checklist used to assess study quality.

++=high quality study, +=acceptable, $0=$ =unacceptable; BMI, body mass index; CVD, cardiovascular disease; GP, general practitioner; RCT, randomised controlled trial. 
correlation was intended). This shows that patients who had higher blood cholesterol were more likely to make dietary changes. Although the method and analysis did not separate out people who were aware of their cholesterol levels in the longitudinal comparisons, the authors concluded that informing patients of their blood cholesterol levels effects an immediate change in dietary habits, and that over all, the change in dietary habits effects a reduction in fat intake and lower CVD risk.

Elton $e t a l^{19}$ used a workplace screening and intervention trial in Manchester, UK to examine if knowledge of cholesterol level led to a reduction in cholesterol over a 13-week period. Participants were randomly allocated to either an intervention group, which received information on their current cholesterol level, or to a control group where this information was not provided. Then all participants attended a health education session about diet. The results demonstrated that the reduction in cholesterol measurements 13 weeks after baseline was greater in intervention participants with initially high $(>6.5 \mathrm{mmol} / \mathrm{L})$ serum cholesterol than in matched control participants (change of -0.29 for intervention participants, $95 \%$ CI -0.48 to -0.11 , but only a change of $-0.01,95 \%$ CI -0.16 to 0.15 for controls, difference between groups reached significance at $\mathrm{p}<0.024)$. A key difference between this and an earlier study, ${ }^{18}$ which had not shown an effect of informing participants of their cholesterol level, was that the interventions specifically focused on diet here, whereas the earlier study delivered a general health education package.

\section{Impact of health dialogue on behaviour change}

Five studies examined the role of health dialogue in influencing health outcomes of screening interventions. ${ }^{20-24}$ Färnkvist et $a l^{20}$ investigated the extent to which health screening with or without health dialogue influenced self-reported CVD and diabetes morbidity 11 years postscreening. Participants were men aged 3555 years in Härnösand, Sweden. Screening included objective measurements (eg, blood pressure), a selfreport questionnaire and health counselling provided by nurses. Although described alternately as health dialogue and counselling in this study, it did actually consist of a structured motivational dialogue that included discussion of the individual's CVD risk, as well as of the possible lifestyle changes, and hence fulfils our definition of a health dialogue. Other healthcare providers in the same community (mainly occupational health services) carried out the same screening but without the health dialogue.

Eleven years later, participants were asked to complete a questionnaire including questions about smoking, alcohol, physical activity, height, weight, fat intake and the presence of CVD and/or diabetes. There was no significant decline in health during the 11 years for those participants who received the screening plus health dialogue (8.2\% incidence of CVD and/or diabetes), in stark contrast to those who received screening only
(22.6\% incidence) or no screening (19.2\%). The OR of developing CVD or diabetes over the 11 years was 2.5 for those who had screening with no health dialogue, and 3.0 for those who had not participated in either the original screening or the dialogue, as compared with the dialogue group. That is, the risk was more than doubled for any group that had not received the dialogue. The authors concluded that screening that includes a structured, motivational health dialogue is more effective than screening without this dialogue.

Engberg et $a l^{21}$ conducted a randomised controlled trial in Denmark investigating the impact of general health screening versus screening plus general practitioner (GP)-patient discussions about CVD risk profile. Randomly selected men aged 30-50 years from several GP practices were sent an invitation letter and postal questionnaire about lifestyle. Those who agreed to take part completed a second questionnaire asking about their health, lifestyle, psychosocial status and life events. Participants were randomised to a control group (questionnaire only, no screening) or one of two intervention groups: screening only and screening plus health discussions (time points not given). Participants in the health screening plus discussion group were offered a $45 \mathrm{~min}$ consultation with their GP to discuss their results and how to adapt to a healthier lifestyle. They were encouraged to set their own topics for discussion and to set health-related lifestyle goals to achieve within the next year. These participants were offered further discussions annually for 5 years. Randomisation to groups was stratified based on the GP with whom they were registered, age, sex, body mass index (BMI) and 'cohabitation status'. All screened participants received personal written feedback from their GPs, including advice on lifestyle change (where necessary) and information leaflets about a healthy lifestyle. All participants were followed up at 1 and 5 years.

At the 5-year follow-up, there were no significant differences in measures of CVD risk factors between the two intervention groups (screening only vs screening plus discussion). Taken together, however, these two intervention groups had a much lower proportion of patients with elevated CVD risk scores than the control group, whose prevalence of elevated CVD risk was approximately twice that of the intervention groups $(\mathrm{RR}=0.54,95 \% \mathrm{CI}=0.40$ to 0.73$)$. However, there were no significant differences between the control and intervention groups for blood pressure, and no effects on smoking. The authors concluded that though the intervention as a whole had a marked effect on CVD risk, the discussions did not improve the cardiovascular health of participants over and above the improvement shown from screening with feedback.

Rubak et $a l^{22}$ examined the difference in patient outcomes (improved metabolic status in patients with diabetes) between those whose GPs had received training in MI and those whose GPs had been allocated to a control group. Both groups of GPs received training in 
intensive treatment of type 2 diabetes. The study found that patients with GPs in both groups showed significant improvements, with no difference between the groups at 1-year follow-up. One explanation for the lack of difference found is that GPs in the motivational interview group had used an average of less than two of the three motivational interview sessions allocated to them. The authors suggest that some contamination of effect may have occurred, in that the control group GPs also became aware of MI, and that the GPs in the motivational interview group did not use it as much as had been recommended.

Koelewijn-van Loon et $a l^{23}$ investigated differences between participants who had a structured dialogue with a trained nurse (including risk assessment, risk communication, motivational interview and a patient 'decision support tool') and patients who received usual care. Outcome measures were self-reported lifestyle behaviours, diet, exercise, smoking and alcohol use, which were measured 12 weeks after baseline to assess change. Five hundred and twenty-two patients completed the follow-up measures. The authors concluded that the results showed an improvement in lifestyle in both groups; there were no differences between groups in terms of effects.

Craigie $e t a t^{24}$ examined the impact of a personalised lifestyle programme (HealthForce) aimed at promoting lifestyle behaviour change and based specifically on health behaviour change theory. HealthForce targeted motivational elements to create intentions to change behaviour and volitional elements, focusing on translating intentions into planned behaviours. It involved patients attending three face-to-face sessions with a trained lifestyle counsellor, plus other materials, with topics being activity, diet and weight management. The outcome assessments all showed significant positive changes for the intervention group (all $\mathrm{p}<0.01$ ), with no positive but some negative changes for the control group. Consumption of five portions of fruit and vegetables a day went from $56 \%$ to $85 \%$ for the intervention group; weight was down by an average of $1.1 \mathrm{~kg}$, BMI went from a mean of $26.7-26.2 \mathrm{~kg} / \mathrm{m}^{2}$ (with increases, rather than decreases, for the control group, $\mathrm{p}<0.01$ ) and waist circumference went from 87.3 to $84 \mathrm{~cm}$ (no significant change for the control group).

The contrast between these five similar studies is striking; Färnkvist $e t a l$ and Craigie $e t a l \mathrm{~s}$ analyses supported the impact of health dialogue, Engberg et al found that screening plus verbal health dialogue was not superior to screening that included a written dialogue, while Rubak et al and Koelewijn-van Loon et al found no effect. However, the outcome measures, and time between measurements, vary across studies; Färnkvist et al compared risk of CVD and diabetes diagnosis over 11 years, Engberg et al assessed differences between groups in risk factors 5 years after initial screening, Rubak et al tested metabolic status in patients with diabetes after 1 year, Koelewijn-van Loon et al compared self-reports of lifestyle behaviours 12 weeks after the intervention, and Craigie et al compared anthropometric and health behaviour changes 12 weeks later. This raises a number of issues. First, endpoint diagnosis is the most objective measure of the impact of intervention, as well as providing the strongest evidence of efficacy. Second, in general, longer term follow-ups are preferable; however, selective attrition could be a greater issue for longer term follow-ups, biasing the sample. Conversely, shorter term follow-ups may not allow enough time for change to happen. Finally, these studies, though conducted with similar samples, were run in four different countries with subsequent differences in healthcare services and risk levels at baseline, and so conclusions need to take into account the healthcare context when assessing the mechanisms and outcomes. ${ }^{7}$

Of particular interest were the two studies which both used self-reported behavioural outcomes and a 12-week follow-up and yet had contradictory results (Craigie et al and Koelewijn-van Loon et $a l$ ). Both included face-to-face counselling on more than one occasion, telephone support sessions and motivational interview plus decision support or goal setting. The most obvious difference is that patients in Craigie $e t a l$ s study were all preselected as high risk (but not on statins), whereas only $28 \%$ of those in Koelewijn-van Loon et als study were designated as high CVD risk. Indeed, the latter study did find a difference between the intervention and control groups in fruit and vegetable consumption when only those with diagnosed diabetes were included. As in previous analyses, the difference seems to be due to the finding that those with a higher perceived risk are more likely to make appropriate changes to their health behaviour. Again, context is highlighted, but here in terms of the individuals one is trying to influence.

\section{Key points}

Providing patients with feedback on screened measurements can promote changes in behavioural intentions and actual health behaviour change.

- The benefits of a structured, motivational health dialogue are supported over simple screening where outcomes are measured in the long term, but the actual structure of such dialogues has not been directly analysed in the literature.

- The comparison of similar studies highlights the need for a set of basic standardised measures.

- Comparisons suggest that longer term influences on disease occurrence need assessing.

- Patients informed that they are at high risk tend to make the most lifestyle changes and achieve the most positive outcomes.

Factors predicting the uptake, attendance and attrition from screening programmes: uptake and invitation

For screening programmes to be cost-effective, it is essential to maintain high levels of uptake and attendance and avoid excessive attrition. Research ${ }^{25}$ has 
demonstrated that some groups, for example, the less healthy, are less likely to participate in screening programmes and more likely to drop out if they do start participating. Attempts have been made to encourage the uptake of screening by manipulating the method of invitation: three studies examined the effect of invitation style on uptake and health outcome. ${ }^{26-28}$

Marteau et $a l^{26}$ hypothesised that providing an informed choice leaflet would lower attendance relative to standard invitations, because individuals receiving the leaflet would see that screening is unlikely to provide individual benefits. The authors found no difference in attendance rates between individuals who received an informed choice letter versus a standard letter, but they did replicate previous studies in finding that attendance fell with increasing social deprivation. There was no interaction between social deprivation and invitation type; however, the authors concluded that the ethical advantage gained in informed choice invitations did not outweigh the attendance benefit of standard invitations.

Park $e t a l^{27}$ investigated the effects of loss-framed and gain-framed messages in an invitation to screen for type 2 diabetes. The loss frame message ('If you have diabetes but are not detected early, your diabetes may lead to more complications') highlights the possible losses due to not attending; the gain frame message ('If your diabetes is detected early, you can receive early and more effective treatment') emphasises the possible gains of attending. Participants aged 40-69 years were randomly selected from two GP practices in Cambridgeshire, England. Fifty-nine patients were randomised to receive the loss-framed invitation and 57 the gain-frame invitation. All invitations included a neutral framed message ('A simple blood test is the best way to detect diabetes').

There were no significant differences in attendance rates between groups (loss-frame $=81 \%$ vs gainframe $=82 \%$ ). Overall, results show that how information was framed made little difference to the attendance rates. There was, however, a significant interaction effect between sex and invitation frame; attendance was higher in men invited using the loss-frame (89\%) compared with the gain-frame $(77 \%)$, and higher in women invited using the gain-frame (94\%) compared with the loss-frame $(68 \%)$. Although this result should be viewed with caution because of the small numbers, it does suggest a potential for using different frames for different patient groups.

In addition to investigating the content and format of invitation letters, researchers have also examined the potential of opportunistic screening, that is, asking patients to complete screening while they are attending a healthcare setting for another purpose, such as collecting medication. Hellénius $e t a t^{28}$ investigated opportunistic screening on visits to a healthcare centre for other purposes in a suburban area of Sweden (Sollentuna). Male and female adults under the age of 60 who visited health centres were opportunistically invited to the screening. This group was compared with a group which was invited by letter. Fifty-nine per cent of those invited by letter participated (249 people) compared with $15 \%$ of the men and $20 \%$ of the women who were invited when they visited their health centres (4655 people, the opportunistic sample). The frequencies of hypertension, high cholesterol and high triglycerides were greater in the opportunistic sample than in the letter-invited sample, but there were no differences in smoking or the likelihood of being overweight. The outcomes of the intervention showed significant blood pressure, cholesterol and triglyceride reductions, but no differences in the level of reductions in risk factors between opportunistic and letter-invited participants. The authors concluded that the integration of a large scale CVD risk screening programme into a regular primary healthcare system was successful and that, taking into account the low uptake, opportunistically screening patients was successful in identifying those with high CVD risk factors whose risk factor level could be reduced.

\section{Difference between attenders and non-attenders}

It has been noted that differences exist between individuals who attend screening and those who do not, ${ }^{25}$ and our search strategy identified two papers on this topic. Jones et $a t^{9}$ recruited 3800 patients (aged 25-55 years) across six GP practices in Wales who were invited for a CHD risk factor screening programme. Two thousand four hundred and two (63.2\%) attended for screening, whereas $1389(36.8 \%)$ did not attend. A 1 in 10 random sample of 140 non-attenders was obtained using a further letter offering them a medical 'MOT' with specific reference made to heart disease and asking them to make an appointment any morning or afternoon. (MOT is an annual car maintenance test which is legally required by the Department of Transport for cars on UK public roads, a term which is very familiar in the UK.) After 3 weeks, any persisting non-respondents were sent another letter including a specific appointment time, asking them to contact the surgery if this was not convenient. A final contact was made by telephone after a further 3 weeks, and the nurse visited the home for the appointment if necessary. This approach resulted in $98(70 \%)$ of the original non-attenders being screened. They were asked to indicate reasons for their initial non-attendance. Reasons (in order of frequency) were: invitation letter not received $(36.7 \%)$; 'practical reasons' $(26.5 \%)$; felt screening was unnecessary because they were feeling well $(18.4 \%)$; already under medical care for CHD-related issues $(12.2 \%)$; already aware of having risk factors and so felt screening was unnecessary (10.2\%); felt apathetic about screening (10.2\%); afraid of screening $(7.1 \%)$; forgot to attend appointment $(4.1 \%)$.

Non-attenders were significantly older than attenders (mean age 42.6 years and 39.4 years, respectively; $\mathrm{p}<0.001,95 \%$ CI of difference $1.50,4.88)$. They were more likely to have lower socioeconomic status (SES) than attenders and more likely to have a personal history of CHD (12\% vs $5.7 \%, \mathrm{p}<0.05)$. In addition, mean BMI $(p<0.01 ; 95 \%$ CI 0.84 to 2.58$)$, cholesterol 
( $\mathrm{p}<0.01,95 \%$ CI 0.26 to 0.74 ) and blood pressure (systolic $\mathrm{p}<0.001 ; 95 \%$ CI 9.57 to 15.86 ; diastolic $\mathrm{p}<0.01$; $95 \%$ CI 1.63 to 5.82 ) were significantly higher for nonattenders than attenders. These results show that those people most in need of healthcare are less likely to access it. However, it is also clear that approximately $22 \%$ of non-attenders did not attend because they were already under medical care for CHD issues or were already aware of their risk factors (no data for attenders), possibly influencing the outcome differences between attenders and non-attenders, and potentially reducing the likelihood of these individuals responding to an invitation for screening.

A further issue of non-attendance is that of differences between people who continue in a programme once they have has started and those who drop out. Thomas et $a l^{30}$ examined the characteristics of attenders and non-attenders at the 20-year follow-up screening in the British Regional Heart Study. The non-attenders referred to here were all people who had attended originally, but failed to return for reassessment, that is, had dropped out. A total of 7735 men took part in the original screening, and $4252(77 \%)$ attended the follow-up. There were no significant differences at baseline in age, BMI and cholesterol between those who attended those and who did not attend at the follow-up, but nonattenders at the follow-up had a higher baseline blood pressure. Questionnaire data on the non-attenders was available from 2 to 4 years before the invitation to the follow-up health check. This showed that they were more likely to have suffered stroke, peripheral vascular disease and bronchitis and that they were twice as likely to smoke cigarettes. Attenders were significantly more likely to be married, to own their own home, to have access to a car and to be educated past the age of 16 .

Mortality rates within 1 year of follow-up were significantly higher among non-attenders than attenders $(6.2 \%$ vs $1.7 \%)$, though the majority of deaths were non CVD-related. Non-attenders who self-reported having poor or fair health and a disability were significantly less likely to attend for follow-up, as were participants who reported using four or more medications regularly. Furthermore, non-attenders were shown to be taking multiple prescribed medications, reporting more disabling conditions and had a high early mortality rate.

\section{DISCUSSION}

This realist review focused on the use of evidence-based design features of interventions which aimed to increase uptake of CVD and diabetes screening with a view to increasing early detection and reduction of risk factors for these diseases. Only 12 studies were identified that critically examined the intervention design and tested the efficacy of health behaviour change components, such as feedback, against health outcomes. Key findings include the following: health-related feedback or health dialogue can be effective, but in order to enable specific analyses, a

\section{Key points}

Informed choice invitations are preferable ethically and do not appear to reduce screening uptake. Framing of invitations to screen may affect attendance rates for men and women; where a screening invitation is gender specific, targeting may benefit from framing.

- Opportunistic screening at visits to GP surgeries for other purposes is shown to be effective

- Evaluation of opportunistic screening confirms that it reaches people with higher CVD risk factors than those reached using standard invitations.

- People screened opportunistically showed very similar improvements in assessed risk factors to people invited in other ways People who do not attend or who drop out at later stages may be different.

- Differences between people who respond to invitations for screening and those who do not are difficult to ascertain, but evidence suggests that non-attenders have higher CVD risk factors.

- Selective dropout ('selective attrition') biases longitudinal studies in that inevitably people who are less healthy, less well educated, of lower SES or with more lifestyle risk factors (smoking, higher alcohol consumption, overweight) are more likely to fail to return for follow-up appointments.

- Selective attrition may result in outcomes in longitudinal studies appearing more positive (overestimate of effect) because the people who remain in the study are healthier.

- Careful methodological and statistical controls are needed to reduce resultant effects on findings.

working definition of what this communication entails is required; whether individuals are invited for screening or are screened opportunistically may influence the nature of participants recruited, with those at higher risk less likely to respond to an invitation; and selective attrition of those at higher risk may be skewing the results of longitudinal studies because it is the healthier, lower risk patients who are most likely to attend for follow-up.

\section{Impact of behavioural features on the quality and outcome of interventions}

It is clear from the studies reviewed that consideration of the evidenced behavioural features of interventions is limited; in particular, several large UK studies ${ }^{25} 3132$ were excluded from the review at an early stage in the search process because they did not examine any design, behavioural or psychological features of screening or intervention. Nevertheless, the studies included in the review indicate several strategies that could be usefully employed to reduce risk in high-risk and general population targets, such as providing opportunistic screening. There was a lack of evidence that intervention design was based on health psychology theory (eg, Ajzen's theory of planned behaviour), ${ }^{33}$ despite research showing that such theories can predict screening attendance, ${ }^{34}$ and lifestyle behaviours that are the target of screening interventions. ${ }^{35}$ Even studies that claimed to be based on theories and target 
motivation ${ }^{24}$ failed to specify the theory base for their intervention. This lack of emphasis on health psychology theories suggests a greater focus on the outcome of the intervention (ie, did people change their behaviour?) rather than a focus on the motivations and perspectives of the individuals invited to screen. This 'one-size fits all' approach to intervention design is unlikely to yield success as research shows that even in a sample of 10 participants not all of them respond positively to the same interventions. ${ }^{36}$ Although there was limited use of health psychology theories in the design of the interventions included in this review, several interventions included elements such as the influence of health dialogue, goal setting and feedback, which have been shown to promote health behaviour change, ${ }^{37} 38$ although much of this research has been conducted outside of primary care settings. Therefore, it was encouraging to find that goal setting promoted changes in outcomes in Craigie et al and that feedback was helpful in Aubin $e t$ al and Elton et al. These elements require further examination with reference to a behaviour change taxonomy, for example, Abraham and Michie's, ${ }^{15}$ to determine whether they are effective within the context of CVD and diabetes screening programmes. Relatedly, an issue highlighted by our evaluation of a CVD screening intervention in the $\mathrm{UK}^{39}$ is the extent to which healthcare practitioners use the strategies and tools with which they have been provided in the health dialogues they have with their patients. This issue of intervention fidelity has the potential to differentiate between programmes that are successful in getting patients to change their behaviour and programmes that are not, ${ }^{40}$ and is evident in Rubak et $a l^{22}$ who found that GPs failed to deliver, on average, more than one session of motivational interview to patients, when they were facilitated to deliver three. CERAG's definition of implementation research: 'the scientific study of methods to promote the systematic uptake of clinical research findings and other evidence-based practices in routine practice, and hence to improve the quality (effectiveness, reliability, safety, appropriateness, equity, efficiency) of healthcare' (cited in Eccles $e t a l^{41}$ ) sets this study firmly in the context of implementation science.

\section{Study limitations}

This review raised two key challenges. First, studies rarely analyse behavioural components of the intervention design discretely, making it impossible to discern which factors are at work in producing the observed effects. Second, the heterogeneity of outcome measures precludes statistical evaluations using meta-analysis. Publication or outcome bias may have affected our results, though not all included studies found significant reductions in assessed risk or differences in outcomes between the intervention and control groups. Several potentially relevant studies that focus on the design of screening interventions were excluded because they were not delivered in healthcare settings. The reviewed studies also highlight the disadvantages of intention-to-treat analyses, which are better suited for assessing the efficacy of an intervention in practice, as opposed to understanding 'how' and 'why' an intervention works, and the need to control for selective attrition either by the use of features which reduce dropout or by statistical control for known differences between returners and non-returners, but few studies employ this. As a realist review, this document examines outcomes which may be situation specific. The acknowledgement that some findings may be situation specific or population specific is important in the generalisation of results.

\section{Conclusions and policy implications}

This review highlights the need for a more systematic approach to the strategic design, conduct and analysis of health interventions by taking into account the complex interactions between the design, delivery, attrition and health outcomes. It is recommended that insights from health psychology should be incorporated in the design of interventions aimed at increasing screening uptake, as well as involving cross-disciplinary specialist areas such as physical activity and nutrition to promote lifestyle behaviour change alongside pharmacological treatment. Furthermore, to control the effects of selective attrition, there is a need to perform sensitivity analyses in order to monitor the make-up of the sample and perhaps some purposive sampling to protect against biasing the sample towards a healthier baseline and therefore reduced effect at follow-up, particularly in longitudinal studies. It is anticipated that such carefully designed interventions would result in health behaviour change that provide as much benefit to the wider population as they do for those with heightened risk, resulting in better overall population outcomes.

Contributors $\mathrm{CH}, \mathrm{RS}, \mathrm{HP}$ and $\mathrm{RC}$ were responsible for the conception and design of the study. YC had the principal responsibility for search and sourcing of articles and initial data extraction, and $\mathrm{RC}$ contributed to reference chaining. $\mathrm{CH}$ and $\mathrm{YC}$ independently reviewed the157 full-text papers retrieved, and further excluded studies which only evaluated changes in risk factors or cost-effectiveness. $\mathrm{CH}$ and RC assigned quality scores to each included full-text article based on the Scottish Intercollegiate Guidelines Network (SIGN 50) quality assessment instruments. $\mathrm{CH}$ had the principal responsibility for data extraction, analysis and interpretation of the data and for drafting the article, revisions and final approval. RS, HP and RC contributed to interpretation of the data, revisions and final article approval. $\mathrm{CH}$ and $\mathrm{RC}$ are the guarantors.

Funding This study is a subsection of a larger review which was commissioned by the Heart of Birmingham teaching and Primary Care Trust, which funded $Y C$ as a Research Associate as part of a larger research project. $\mathrm{CH}, \mathrm{HP}, \mathrm{RC}$ and RS are all members of the Health and Lifespan Psychology Research group working at Aston University. The funders had no role in the design of this review, the data collection, analysis and interpretation, writing the manuscript or in the decision to submit the research for publication.

\section{Competing interests None.}

Provenance and peer review Not commissioned; externally peer reviewed.

Data sharing statement No additional data are available.

Open Access This is an Open Access article distributed in accordance with the Creative Commons Attribution Non Commercial (CC BY-NC 3.0) license, which permits others to distribute, remix, adapt, build upon this work noncommercially, and license their derivative works on different terms, provided the original work is properly cited and the use is non-commercial. See: http:// creativecommons.org/licenses/by-nc/3.0/ 


\section{REFERENCES}

1. Ebrahim S, Beswick A, Burke M, et al. Multiple risk factor interventions for primary prevention of coronary heart disease. Cochrane Database Syst Rev 2006;(4):CD001561.

2. Allender S, Peto V, Scarborough $\mathrm{P}$, et al. Coronary heart disease statistics. London: British Heart Foundation, 2008.

3. Unal B, Critchley JA, Capewell S. Modelling the decline in coronary heart disease deaths in England and Wales, 1981-2000: comparing contributions from primary prevention and secondary prevention. BMJ 2005;331:614-19.

4. NHS Health Check programme. 2012. http://www.healthcheck.nhs.uk

5. Petticrew M. 'More research needed'. Plugging gaps in the evidence base on health inequalities. Eur J Public Health 2007;17:411-13.

6. Grimshaw JM, Eccles MP, Lavis JN, et al. Knowledge translation of research findings. Implement Sci 2012;7:50

7. Pawson R, Greenhalgh T, Harvey G, et al. Realist review-a new method of systematic review designed for complex policy intervnetions. J Health Serv Res Policy 2005;10(Suppl 1):21-34

8. McMahon T, Ward P R. HIV among immigrants living in high-income countries: a realist review of evidence to guide targeted approaches to behavioural HIV prevention. Syst Rev 2012;1:56.

9. Moher D, Liberati A, Tetlaff J, et al. Preferred reporting items for systematic reviews and meta-analyses: the PRISMA statement. BMJ 2009;339:b2535-6.

10. Flight IHK, Wilson CL, Griffiths L, et al. Interventions for improving uptake of population-based screening for colorectal cancer using fecal occult blood testing. Cochrane Database Syst Rev 2004;(4): CD005035.

11. Forbes C A, Jepson RG, Martin-Hirsch PPL. Interventions targeted at women to encourage the uptake of cervical screening. Cochrane Database Syst Rev 2002;(3):CD002834.

12. Scottish Intercollegiate Guidelines Network (SIGN 50) methodology checklists. Circa 2001-2013, updated 15 Apr 2013, http://www.sign. ac.uk/guidelines/fulltext/50/checklist3.html

13. Shahab L, Hall S, Marteau T. Showing smokers with vascular disease images of their arteries to motivate cessation: a pilot study. Br J Health Psychol 2007;12:275-83.

14. Shahab L, West $R$, McNeill A. A randomized, controlled trial of adding expired carbon monoxide feedback to brief stop smoking advice: evaluation of cognitive and behavioral effects. Health Psychol 2011;30:49-57.

15. Abraham C, Michie S. A taxonomy of behaviour change techniques used in interventions. Health Psychol 2008;27:379-87.

16. Michie S, Ashford S, Sniehotta FF, et al. A refined taxonomy of behaviour change techniques to help people change their physical activity and health eating behaviours: the CALO-RE taxonomy. Psychol Health 2011;26:1479-98.

17. Robertson I, Phillips A, Mant D. Motivational effect of cholesterol measurement in general practice health checks. Br J Gen Pract 1992;42:469-72.

18. Aubin M, Godin G, Vézina L, et al. Hypercholesterolemia screening Does knowledge of blood cholesterol level affect dietary fat intake? Can Fam Physician 1998;44:1289-97.

19. Elton PJ, Hammer M, Page F. Randomised controlled trial in northern England of the effect of a person knowing their own serum cholesterol concentration. J Epidemiol Commun Health 1994;48:22-5.

20. Färnkvist L, Olofsson N, Weinehall L. Did a health dialogue matter? Self-reported cardiovascular disease and diabetes 11 years after health screening. Scand J Prim Health Care 2008;26:135-9.

21. Engberg M, Christensen B, Karlsmose B, et al. General health screenings to improve cardiovascular risk profiles: a randomised controlled trial in general practice with 5-year follow-up. J Fam Pract 2002;51:546-52.

22. Rubak S, Sandbaek A, Laurtizen T, et al. Effect of 'motivational interviewing' on quality of care measures in screen detected type 2 diabetes patients: a one year follow-up of and RCT, ADDITION Denmark. Scand J Prim Health Care 2011;29:92-8.

23. Koelewijn-van Loo MS, van der Weijden T, Ronda G, et al. Improving lifestyle and risk perception through patient involvement in nurse-led cardiovascular risk management: a cluster-randomised controlled trial in primary care. Prev Med 2010;50:35-44.

24. Craigie AM, Barton KL, Macleod M, et al. A feasibility study of a personalised lifestyle programme (Healthforce) for individuals who have participated in cardiovascular screening. Prev Med 2011;52:387-9.

25. Wood DA, Kinmonth AL, Davies GAY, et al. Randomised controlled trial evaluating cardiovascular screening and intervention in general practice: principal results of British family heart study. BMJ 1994;308:313-20.

26. Marteau TM, Mann E, Prevost AT, et al. Impact of an informed choice invitation on uptake of screening for diabetes in primary care (DICISION): randomised trial. BMJ 2010;340:c2138.
27. Park $\mathrm{P}$, Simmons RK, Prevost AT, et al. A randomized evaluation of loss and gain frames in an invitation to screening for type 2 diabetes: effects on attendance, anxiety and self-rated health. $J$ Health Psychol 2010;15:196-204.

28. Hellénius M L, Johansson J, de Faire U, et al. Four years experience of cardiovascular opportunistic screening and prevention programme in the primary health care in Sollentuna, Sweden. Scand J Prim Health Care 1999;17:111-15.

29. Jones A, Cronin P A, Bowen M. Comparison of risk factors for coronary heart disease among attenders and non-attenders at a screening programme. Br J Gen Pract 1993;43:375-7.

30. Thomas MC, Walker M, Lennon L T, et al. Non-attendance at re-examination 20 years after screening in the British Regional Heart Study. J Public Health Med 2002;24:285-91.

31. Muir J, Lancaster T, Jones L. The Imperial Cancer Research Fund OXCHECK Study Group. Effectiveness of health checks conducted by nurses in primary care: final results from the OXCHECK study. BMJ 1995;310:1099-104

32. Muir J, Mant D, Jones L, et al. Effectiveness of health checks conducted by nurses in primary care: results of the OXCHECK study. BMJ 1994;308:308-12.

33. Ajzen I. The theory of planned behavior. Organisational Behav Hum Decis Process 1991;51:179-211.

34. Cooke R, French DP. How well do the theory of reasoned action and theory of planned behaviour predict screening attendance? A meta-analysis. Psychol Health 2008;23:745-65.

35. McEachan RRC, Conner M, Taylor NJ, et al. Prospective prediction of health-related behaviours within the theory of planned behaviour: a meta-analysis. Health Psychol Rev 2011;5:97-144.

36. Sniehotta FF, Presseau J, Hobbs N, et al. Testing self-regulation interventions to increase walking using factorial randomised N-of-1 trials. Health Psychol 2012;31:733.

37. Gollwitzer PM, Sheeran P. Implementation intentions and goal achievement: a meta-analysis of effects and processes. In Zanna MP. ed. Advances in experimental social psychology. New York Academic Press, 2006;39:69-119.

38. Gill J, O'May F. Practical demonstration of personal daily consumption limits: a useful intervention tool to promote responsible drinking among UK adults? Alcohol Alcohol 2007;42:436-41.

39. Cooke R, Shaw R, Holland $\mathrm{C}$, et al. Evaluation of the cardiovascular screening programme in the Heart of Birmingham region: a study about perspectives on screening. A report to Birmingham \& Solihull NHS Cluster, 2012.

40. Borrelli B, Sepinwall D, Ernst D, et al. A new tool to assess treatment fidelity and evaluation of treatment fidelity across 10 years of health behaviour research. J Consult Clin Psychol 2005;73:852-8.

41. Eccles MP, Armstrong A, Baker R, et al. An implementation research agenda. Implement Sci 2009;4:18.

\section{APPENDIX}

1. Search terms used in search strategy

The following terms were used in all data sources: (cardiovascular OR vascular OR CVD OR 'chronic heart disease' OR 'coronary heart disease' OR CHD OR diabetes) AND ('mass screening' OR surveillance $^{\star}$ ) AND (letter OR mail* OR phone OR telephone OR 'reminder system*' OR 'videotape recording" OR 'audiotape recording"' OR questionnaire* OR strateg* OR alert* OR hotline OR community OR media) AND (intervention* OR goal OR 'behav* change' OR 'implementation intention*' OR plans OR planned OR planning OR plan OR educat* OR campaign* OR barriers OR intention* OR 'behav* outcome' OR outcome OR 'lifestyle change' OR longitudinal OR 'follow up' OR motivation*) AND (satisf* OR dropout* OR 'drop out' OR attrition OR uptak* OR adher* OR compliance OR complie* OR comply* OR 'patient acceptance of health care' OR encourag* OR improve* OR improving OR increas* OR promot* OR particip* OR nonattend* OR 'non attend' OR accept* OR attend* OR attitud* OR utilisation OR utilization OR refus* OR respond* OR respons* OR reluctan* OR nonrespon* OR 'non respon*' OR incidence OR prevalence OR prevelence OR satisfaction OR cooperat* OR 'co operat' ${ }^{\star}$ ) AND (findings OR interview* OR qualitative OR experienc* OR RCT OR 'randomised controlled trial' OR trial). 